\title{
Emergency Department Waiting Times and Determinants of Prolonged Length of Stay in a Botswana Referral Hospital
}

\author{
Keatlaretse Siamisang ${ }^{1,2}$, John Thato Tlhakanelo1, Bonolo Bonnie Mhaladi² \\ ${ }^{1}$ University of Botswana, Gaborone, Botswana \\ ${ }^{2}$ Botswana Ministry of Health and Wellness, Gaborone, Botswana \\ Email: ^drksiamisang@gmail.com
}

How to cite this paper: Siamisang, K., Tlhakanelo, J.T. and Mhaladi, B.B. (2020) Emergency Department Waiting Times and Determinants of Prolonged Length of Stay in a Botswana Referral Hospital. Open Journal of Emergency Medicine, 8, 59-70. https://doi.org/10.4236/ojem.2020.83007

Received: June 9, 2020

Accepted: July 20, 2020

Published: July 23, 2020

Copyright $\odot 2020$ by author(s) and Scientific Research Publishing Inc. This work is licensed under the Creative Commons Attribution International License (CC BY 4.0).

http://creativecommons.org/licenses/by/4.0/

(c) (i) Open Access

\begin{abstract}
Introduction: Emergency medicine is a critical component of quality public health service. In fact length of stay and waiting times in the Emergency department are key indicators of quality. The aim of this study was to determine waiting times and determinants of prolonged length of stay (LOS) in the Princess Marina Hospital Emergency Department. Methods: This was a retrospective observational study. It was done at Princess Marina, a referral hospital in Gaborone, Botswana. Triage forms of patients who presented between 19/11/ 2018 and 18/12/2018 were reviewed. Data from patient files was used to determine time duration from triage to being reviewed by a doctor, time duration from review by emergency doctor to patients' disposition and the time duration from patient's triage to disposition (length of stay). Prolonged length of stay was defined as duration $>6$ hours. Results: A total of 1052 files representing patients seen over a 1-month period were reviewed. $72.5 \%$ of the patients had a prolonged length of stay. The median emergency doctor waiting time was 4.5 hours (IQR $1.6-8.3$ hours) and the maximum was 27.1 hours. The median length of stay in the emergency department was 9.6 hours (IQR 5.8 - 14.6 hours) and the maximum was 45.9 hours. Patient's age (AOR 1.01), mental status (AOR 0.61), admission to internal medicine service (AOR 5.12) and pediatrics admissions (AOR 0.11) were significant predictors of prolonged length of stay in the emergency department. Conclusion: Princess Marina Hospital emergency department waiting times and length of stay are long. Age, normal mental status and internal medicine admission were independent predictors of prolonged stay ( $>6$ hours). Admission to the pediatrics service was associated with shorter length of stay. There is a need for interventions to address the long waiting times and length of stay. Interventions should particularly focus on the identified predictors.
\end{abstract}




\section{Keywords}

Emergency Department, Waiting Times, Prolonged Length of Stay, Determinants

\section{Background}

For many years, emergency medicine has been recognized as a critical component of quality public health service [1]. The World Health Organization (WHO) recognizes emergency care not only as an essential component of universal health care but also as vital in achieving the Sustainable Development Goals (SDGs) [2]. Ensuring healthy lives and promoting wellbeing for all at all ages by 2030 is the target of the third SDG [3]. Emergency care plays a significant role in all the components of this goal by among others prompt treatment of acute childhood illnesses, efficient treatment of obstetric emergencies and management of acute exacerbation and complications of non-communicable diseases [2] [3]. A significant proportion of death and disability in low and middle-income countries can be prevented by comprehensive and effective emergency systems [4].

Provision of quality emergency services is hampered by delays in the emergency department (ED). In fact emergency length of stay (LOS) is a key indicator of quality of care of health facilities and health departments [5]. It can therefore be used for performance monitoring and improvement of service. Prolonged stay causes overcrowding that causes further delays resulting in a vicious cycle. Prolonged waiting times not only reduce quality of care but also increase adverse events including more frequent complications and mortality [1] [6]. Hospitals and health departments strive to reduce prolonged stay and overcrowding in emergency departments. This is a difficult task when there is no evidence to guide targeted efforts and public health interventions. Emergency departments are the main hospital entry points for critical and stable patients. Clients can access the services at any time without need for appointment or referral. They may also be the only readily available and accessible means of medical care for patients. The departments therefore occupy a crucial position in the medical care continuum [7]. Improving the performance of emergency departments should be a public health priority since the demand for emergency care is increasing annually across the globe and Botswana is no exception [8]. To this end there is need for locally relevant and up-to-date evidence to guide the country on keeping up with the demand for this vital service. Currently, there are no studies on waiting times and determinants of length of stay in Botswana.

The aim of this study was to determine waiting times and determinants of prolonged length of stay (LOS) in the Princess Marina Hospital Emergency Department. 


\section{Methods}

\subsection{Study Design}

This was a retrospective observational study of the patients waiting times and length of stay in the emergency department.

\subsection{Study Site}

The study was done at Princess Marina Hospital in Gaborone, the capital city of Botswana: one of the three referral hospitals in the country. It is the busiest and largest hospital in the country with a capacity of 567 beds and an average of 750 inpatients. The hospital covers all critical patients from Greater Gaborone and from the referring hospitals around the country [9]. There is a designated triage room and 13 beds including 2 resuscitation beds and 1 isolation bed. About 70 patients are seen daily in the department. As of January 2019, there were 3 emergency physicians, 10 medical officers and 25 nurses working in the department.

\subsection{Study Population}

All triage forms of patients who presented to the Princess Marina hospital during a 1-month period (19/11/2018 to 18/12/2018) were reviewed. No patients who went through the accident and emergency were excluded. The trial period of 1 month is comparable to similar studies in the region [10] [11].

\subsection{Data Collection}

Routinely collected data was extracted from patients' triage forms and entered into Microsoft excel. The following times were documented:

- Patient's registration time

- Time of triage

- Time reviewed by emergency department doctor

- Time of disposition (Time the patient left the Emergency department)

From these times, the following durations were calculated:

- Time from triage until review by emergency doctor (waiting time)

- Time duration from review by medical officer to disposition

- Time duration from triage to disposition (length of stay)

The following additional information was collected

- Patient's acuity scale (South African Triage System (SATS) color code)

- Specialty called and specialty that reviewed patient

- History of trauma

- Mobility status

Day and shift of Emergency department visit were also noted as were demographic information and initial assessment provided on the patients' triage forms.

\subsection{Data Analysis}

A data extraction sheet was used for all collected data. The data was entered into 
Microsoft excel. After data cleaning and preparation, EpiInfo version 7.1, 2019 was used for data analysis. Categorical data was summarized with frequencies and percentages while numeric data was summarized with medians and interquartile ranges. Pearson's Chi-square test or Fisher's exact test were used to determine significant differences in categorical variables while Mann-Whitney's test was used for continuous data. Bivariate and multiple logistic regression analysis were used to determine factors associated with prolonged length of stay. Prolonged length of stay was defined as duration greater than 6 hours. Multiple logistic regression was also used to identify factors associated with an Emergency department length of stay $>12$ hours. A p value of 0.25 was used as a cut-off point to recruit variables from the bivariate model into the multiple regression models. A p value of $<0.05$ was considered significant in the multivariate model. Variables with significant missing data were excluded from the analysis. For other variables, missing data is presented as not documented.

\subsection{Ethical Issues and Protection of Human Subjects}

Ethics approval was sought and obtained from The University of Botswana Ethics review board and the Ministry of Health Human Research and Development Committee. Permission was also sought and obtained from the Princess Marina management. This study only used routinely collected patient data. The participants were not subjected to any additional procedures or activities that may harm or cause them any discomfort or inconvenience. Patients clinical and laboratory data was presented in a way that could not compromise their privacy or confidentiality.

\section{Results}

Of the 1052 files analyzed, 763 (72.5\%) had prolonged length of stay according to the definition. This group of patients had a median age of 32 years while the patients with acceptable length of stay had a median age of 24 years. There were more females than males in both groups accounting for $59.5 \%$ and $52.9 \%$ in the prolonged and acceptable length of stay groups respectively. $36.7 \%$ of study participants had a LOS of $>12$ hours. Table 1 shows the characteristics of patients with Emergency Department length of stay $>6$ hours (prolonged length of stay) and patients with length of stay of 6 hours or less. The median waiting time for review by a medical officer was 4.5 hours while the median length of stay in the Emergency department was 9.6 hours. The maximum length of stay was 45.9 hours (Table 2).

Variables that were significantly associated with prolonged length of stay in the univariate analysis were patient's age, acuity of presentation, patient's mental status, mobility, emergency shift at presentation, admission to internal medicine service, admission to gynecology service and admission to pediatrics service

(Table 3). Increasing age (AOR 1.015), lower mental status (AOR 0.615), not being admitted to Internal Medicine service (AOR 0.344) and admission to 
Table 1. Characteristics of patients with acceptable and prolonged Length of Stay.

\begin{tabular}{|c|c|c|c|}
\hline Variable n (\%) & $\begin{array}{c}\text { LOS }<6 \text { hours } \\
\mathrm{n}=289(27.5 \%)\end{array}$ & $\begin{array}{c}\text { LOS }>6 \text { HOURS } \\
\mathrm{n}=763(72.5 \%)\end{array}$ & $\mathrm{P}$ value \\
\hline Age, median (IQR) & $24(7-37)$ & $32(24-44)$ & 0.001 \\
\hline Sex & & & 0.05 \\
\hline Female & $153(52.9)$ & $454(59.5)$ & \\
\hline Male & $136(47.1)$ & $309(40.5)$ & \\
\hline Acuity (triage) code & & & 0.01 \\
\hline Not documented & $10(5.9)$ & $16(2.1)$ & \\
\hline Green (Routine) & $0(0)$ & $2(0.3)$ & \\
\hline Yellow (Urgent) & $61(21.1)$ & $125(16.4)$ & \\
\hline Orange (Very urgent) & $191(66.1)$ & $580(76.0)$ & \\
\hline Red (Emergency) & $27(9.3)$ & $40(5.2)$ & \\
\hline Mobility & & & $<0.001$ \\
\hline Ambulant & $175(60.6)$ & $527(69.1)$ & \\
\hline Wheelchair & $7(2.4)$ & $43(5.6)$ & \\
\hline Stretcher & $61(21.1)$ & $172(22.5)$ & \\
\hline Not applicable & $46(15.9)$ & $21(2.7)$ & \\
\hline Day of presentation & & & 0.11 \\
\hline Weekday & $208(72.0)$ & $587(76.9)$ & \\
\hline Weekend & $81(28.0)$ & $176(23.1)$ & \\
\hline Shift at presentation & & & 0.02 \\
\hline Day & $242(83.7)$ & $585(76.7)$ & \\
\hline Night & $47(16.2)$ & $178(23.3)$ & \\
\hline History of Trauma & $53(18.3)$ & $134(17.6)$ & 0.67 \\
\hline Disposition & & & 0.72 \\
\hline Discharged & $125(43.3)$ & $319(41.8)$ & \\
\hline Not discharged & $164(56.8)$ & $444(58.2)$ & \\
\hline
\end{tabular}

Table 2. Waiting times and Length Of Stay (LOS) in the emergency department.

\begin{tabular}{ccc}
\hline Time (Hours) & Median (IQR) & Range \\
\hline Medical officer waiting times & $4.45(1.62-8.30)$ & $0.00-27.08$ \\
Length of time from MO review to disposition & $3.90(1.80-7.32)$ & $0.00-34.18$ \\
Length of stay in ED & $9.60(5.83-14.61)$ & $0.75-45.92$ \\
\hline
\end{tabular}

Table 3. Predictors of prolonged length of stay (univariate model).

\begin{tabular}{cccc}
\hline Variable & Unadjusted OR & 95\% CI & P value \\
\hline Age & 1.0279 & $1.0194-1.0365$ & $<0.005$ \\
Sex (male/female) & 0.7692 & $0.5840-1.0131$ & 0.062 \\
Acuity (emergency/non-emergency) & 0.5367 & $0.3228-0.8921$ & 0.016 \\
History of trauma (yes/no) & 0.9115 & $0.6402-1.2977$ & 0.607 \\
\hline
\end{tabular}


Continued

\begin{tabular}{cccc}
\hline Mental status (Not Alert/ Alert) & 0.4748 & $0.2849-0.7915$ & 0.004 \\
Patient disposition (not discharged/Discharged) & 1.0610 & $0.8070-1.3948$ & 0.672 \\
Mobility (non-ambulant/ambulant) & 0.6874 & $0.5188-0.9109$ & 0.009 \\
Day of presentation (Weekend/weekday) & 0.7704 & $0.5652-1.0501$ & 0.098 \\
Day Shift (Yes/No) & 0.7164 & $0.5444-0.9429$ & 0.017 \\
Night shift (Yes/No) & 1.5606 & $1.0914-2.2317$ & 0.015 \\
Medicine admission (No/Yes) & 0.2803 & $0.1637-0.4799$ & $<0.005$ \\
Gynaecology Admission (Yes/No) & 0.6535 & $0.4422-0.9660$ & 0.033 \\
Orthopaedics Admission (No/Yes) & 1.4321 & $0.7685-2.6687$ & 0.258 \\
Surgery Admission (Yes/No) & 1.5257 & $0.9041-2.5747$ & 0.114 \\
Paediatric Admission (Yes/No) & 0.0502 & $0.0224-0.1128$ & $<0.005$ \\
\hline
\end{tabular}

pediatrics service (AOR 0.11) remained statistically significantly associated with prolonged length of stay in the multivariate logistic regression model (Table 4). Age (AOR 1.01), Mental status, mobility, day of presentation and shift, admission to medical and pediatrics services were independent predictors of length of stay greater than 12 hours (Table 5).

\section{Discussion}

This study was the first formal objective measure of the timeliness of Emergency Department (ED) services in Botswana. Previous studies have focused on determining the validity and reliability of formal triage scales [12] [13] [14]. This measurement is imperative as waiting times and length of stay impact access to healthcare and therefore can affect the country's achievement of universal health coverage [15].

The times from triage to medical officer review and from medical officer review to disposition were both long and were comparable. The median waiting time from triage to review by medical officer was 4.45 hours with a maximum waiting time of 27.08 hours. The waiting times are much longer than reported elsewhere [16] [17]. Shorter waiting times were reported in two South African studies. In a Cape Town referral hospital, the median waiting time was 4.1 hours and 2.4 hours before and after introduction of the Cape triage score respectively [18]. A review of data from 52 Western Cape facilities revealed an overall mean waiting time of 2.1 hours [5]. The relatively poor performance of Princess Marina Hospital ED may be due to an overwhelmed system. The ED covers greater Gaborone and referrals from the rest of the country. Medical officers on duty often struggle to keep up with the ever-increasing patient load. The median length of time from review by medical officers to disposition from the Emergency Department was 3.9 hours with a maximum of 34.18 hours. This is the time when most investigations are done and when referrals are made to various specialties. ED medical officers also make decisions about discharge or referral 
Table 4. Predictors of prolonged length of stay (Multivariate model).

\begin{tabular}{cccc}
\hline Variable & Adjusted OR & $95 \%$ CI & P value \\
\hline Age & 1.0149 & $1.0058-1.0240$ & $<0.005$ \\
Sex (male/female) & 0.8940 & $0.6423-1.2443$ & 0.507 \\
Acuity (emergency/non-emergency) & 0.7019 & $0.3702-1.3311$ & 0.278 \\
Mental status (Not Alert/Alert) & 0.6148 & $\mathbf{0 . 3 2 6 0 - 1 . 1 5 9 6}$ & $\mathbf{0 . 0 0 3}$ \\
Mobility (non-ambulant/ambulant) & 0.8137 & $0.5766-1.1485$ & 0.241 \\
Day of presentation (Weekend/weekday) & 0.8047 & $0.5714-1.1333$ & 0.214 \\
Day Shift (Yes/No) & 0.7336 & $0.5238-1.0274$ & 0.072 \\
Night shift (Yes/No) & 1.4034 & $0.9091-2.1666$ & 0.126 \\
Internal Medicine admission (No/Yes) & $\mathbf{0 . 3 4 4 4}$ & $\mathbf{0 . 1 9 3 6 - 0 . 6 1 2 8}$ & $<0.005$ \\
Gynaecology Admission (Yes/No) & 0.7902 & $0.5051-1.2363$ & 0.303 \\
Orthopaedics Admission (No/Yes) & 1.3213 & $0.6775-2.5771$ & 0.414 \\
Surgery Admission (Yes/No) & 1.7217 & $0.9739-3.0437$ & 0.098 \\
Paediatric Admission (Yes/No) & $\mathbf{0 . 1 1 0 1}$ & $\mathbf{0 . 0 4 5 5 - 0 . 2 6 5 5}$ & $<0.005$ \\
\hline
\end{tabular}

Table 5. Predictors of emergency length of stay greater than 12 hours.

\begin{tabular}{cccc}
\hline Variable & Adjusted OR & $95 \%$ CI & P value \\
\hline Age & 1.0111 & $1.0031-1.0191$ & 0.006 \\
Sex (male/female) & 0.9805 & $0.7245-1.3271$ & 0.899 \\
Acuity (emergency/non-emergency) & 0.6183 & $0.3152-1.2129$ & 0.162 \\
Mental status (Not Alert/ Alert) & 0.3013 & $0.1354-0.6704$ & 0.003 \\
Mobility (non-ambulant/ambulant) & $\mathbf{0 . 6 3 8 9}$ & $\mathbf{0 . 4 6 4 1 - 0 . 8 7 9 5}$ & $\mathbf{0 . 0 0 6}$ \\
Day of presentation (Weekend/weekday) & $\mathbf{0 . 7 0 2 2}$ & $\mathbf{0 . 5 0 7 5 - 0 . 9 7 1 6}$ & $\mathbf{0 . 0 3 2}$ \\
Day Shift (Yes/No) & $\mathbf{0 . 5 4 0 0}$ & $\mathbf{0 . 3 9 6 5 - 0 . 7 3 5 4}$ & $<0.005$ \\
Night shift (Yes/No) & 1.2294 & $0.8622-1.7529$ & 0.2540 \\
Medicine admission (No/Yes) & $\mathbf{0 . 3 6 1 7}$ & $\mathbf{0 . 2 4 0 2 - 0 . 5 4 4 6}$ & $<0.005$ \\
Gynaecology Admission (Yes/No) & 0.6999 & $0.4656-1.0132$ & 0.058 \\
Orthopaedics Admission (No/Yes) & 0.6999 & $0.3623-1.3523$ & 0.288 \\
Surgery Admission (Yes/No) & 1.5062 & $0.9269-2.4475$ & 0.098 \\
Paediatric Admission (Yes/No) & $\mathbf{0 . 2 3 7 1}$ & $\mathbf{0 . 0 6 9 4 - 0 . 8 1 0 1}$ & $<0.021$ \\
\hline
\end{tabular}

for further management. The Princess Marina Hospital ED triage form provides for ED medical officers to document when they call other departments for further review and management, what specialty they call and when the specialized teams review patients. Unfortunately, this was poorly documented and therefore was not analyzed. Delayed consultations after referral, multiple referrals, conflicts between ED staff and consultants and multiple investigations have been cited as causes of this delay [19] [20] [21]. 
Prolonged Length of stay (LOS) is not only an independent predictor of mortality and poor outcomes but is also a cause of ED overcrowding [16] [17] [22] [23]. Overcrowding in turn causes stress and burnout among ED healthcare providers and is a major cause of patients' dissatisfaction. Emergency department length of stay greater than 6 hours is widely considered as prolonged [19] [21] [22] [24]. In other settings, LOS of $<4$ hours is considered acceptable [23]. The waiting times and the length of stay in the Princess Marina Emergency department were long. LOS was $>6$ hours for $72.5 \%$ of patients. The median LOS was 9.6 hours with a maximum of 45.9 hours. This was much higher than in an Iranian study where only $10.2 \%$ of patients had prolonged LOS [19]. In a Netherlands hospital $80 \%$ of patients had an ED LOS of $<4$ hours [23]. Researchers in Switzerland reported a significantly lower median LOS of 4.82 hours in a University hospital [25]. Horwitz et al. reported a median ED LOS of 4.3 hours for admitted patients and 2.3 hours for discharged patients across 364 American hospitals [16]. Studies on length of stay in our setting are scarce. The Princess Marina Hospital ED department still performed poorly even when 12 hours was used as a cutoff for prolonged LOS. Only $64.35 \%$ of patients left the ED within 12 hours of their triage.

Increasing age, normal mental status and admission to internal Medicine service were associated with prolonged LOS. Admission to pediatric service was associated with lower odds of prolonged length of stay. Older age has been associated with prolonged LOS in a previous study. It was associated with a 5\% increase in the odds of prolonged LOS in an Iranian hospital [19]. Other significant predictors of prolonged LOS in the study were, lack of insurance support and high number of ordered clinical tests. Unfortunately, data on these factors was not documented in the Princess Marina Hospital ED triage forms. In Saudi Arabia, laboratory time, patient admission to observation, patient admission to trauma, and critical care management and consultation time were significant predictors of prolonged hospital stay [26].

Patients with lower mental status are likely to be more critical and require intensive care. These patients tend to have expedited review and admission. Admission to internal Medicine may be associated with more investigations that could prolong LOS. The prolonged LOS could also be explained by a higher number of internal medicine admissions. Generally, in the Princess Marina Hospital ED, patients can only be admitted after the ward team has reviewed them. Documentation of time of referral and time of review would reveal if the delays were mainly before or after referral to internal medicine service. ED doctors can use their discretion to admit pediatric patients directly without approval of a ward doctor. It is therefore not surprising that these patients had shorter LOS compared to other patients. In addition to the factors described above, 2 other factors were independently associated with an LOS of $>12$ hours. Presentation during day shift was associated with a $46 \%$ reduction in the odds of LOS $>12$ hours. Similarly weekend presentations were associated with a $30 \%$ reduction in odds of prolonged LOS. 
Measures to address the long waiting times and length of stay are required including adequate, skilled and experienced staff. Interventions should focus on the identified predictors of prolonged length of stay. The hospital management should consider allowing ED doctors to use their discretion to admit patients directly to the wards. This is already done for admission to pediatric service which was associated with shorter length of stay. This reduction in length of stay has been associated with less adverse events. Staying in the ED for less than 2 hours reduced the odds of mortality by $79 \%$ compared to LOS $>6$ hours in a Canadian study [27]. Future studies should break down the time from review by ED medical officers to disposition. This would help isolate the sources of delay. In addition, documentation in the ED should be reinforced to allow more detailed analysis of waiting times.

\section{Limitations}

This was a retrospective study using triage form duplicates kept in the Emergency Department. Inevitably, there were missing forms and missing data. Due to system downtime, many patients did not have a registration time. The triage time was therefore used as arrival time for all patients. This could underestimate the length of stay and actual patient times. However, triage is usually done very soon after arrival and is sometimes done even before registration. Time of triage is therefore a reasonable estimate of the patient's arrival time in the Emergency department.

Due to inconsistent documentation, the time from review by medical officer to disposition could not be broken down into smaller time durations i.e. time to referral of patient, time from referral to review by specialty, time from review by specialty admission/discharge and time from admission/discharge to actual departure from the ED. A closer look at these durations would have been critical in identifying areas for action by the hospital management and Ministry of Health. There is a need to reinforce consistent documentation by ED and other hospital staff, especially between the times patients are seen by ED medical officers, to the time they leave the ED. Future studies should include analysis of these times.

\section{Conclusion}

Princess Marina Hospital emergency department waiting times and length of stay are long. Younger age, normal mental status and internal medicine admission were independent predictors of prolonged stay ( $>6$ hours). Admission to pediatrics service was associated with shorter LOS. The documentation of patients' throughput in the ED is suboptimal and needs enforcement.

\section{Acknowledgements}

We will like to thank the management of Princess Marina Hospital for their support and facilitation of this project. We also acknowledge the management and staff of the Emergency department. We also thank the following individuals 
who helped with the collection of data: Sefularo Modukanele, Kevin Tshivhidzo, Pako Kgwarana, Ada Legesse, Thompho Bareetsi and Tsholofelo Seleta.

\section{Dissemination of Results}

The results of this study were shared with the hospital management at the management meeting.

\section{Authors Contributions}

Authors contributed to the conception or design of the work; the acquisition, analysis, or interpretation of data for the work; and drafting the work or revising it critically for important intellectual content. KS designed and drafted the protocol, led the data collection, data analysis and drafted the manuscript. JTT reviewed the protocol, supervised the data collection and critically revised the manuscript for intellectual content. BBM reviewed the protocol, collected data and critically reviewed the manuscript. All authors approved the version to be published, and agreed to be accountable for all aspects of the work.

\section{Conflicts of Interest}

The authors declared no conflicts of interest.

\section{References}

[1] Chaou, C.H., Chiu, T.F., Yen, A.M.F., Ng, C.J. and Chen, H.H. (2016) Analyzing Factors Affecting Emergency Department Length of Stay-Using a Competing RiskAccelerated Failure Time Model. Medicine (United States), 95, e3263. https://doi.org/10.1097/MD.0000000000003263

[2] Reynolds, T. (2015) Emergency, Trauma and Acute Care Department for Management of Non-Communicable Diseases, Disability, Violence and Injury Prevention WHO Emergency Care.

http://www.who.int/global-coordination-mechanism/news/NCDI-reynolds-toroyan .pdf

[3] UN News Centre (2015) UN Adopts New Global Goals, Charting Sustainable Development for People and Planet by 2030.

http://www.un.org/en/development/desa/news/sustainable/un-adopts-new-global-g oals.html\#more-15178

[4] Meyer, G.D., Meyer, T.N. and Gaunt, C.B. (2018) Validity of the South African Triage Scale in a Rural District Hospital. African Journal of Emergency Medicine, 8 , 145-149. https://doi.org/10.1016/j.afjem.2018.07.004

[5] Cohen, K. and Bruijns, S. (2018) Describing Key Performance Indicators for Waiting Times in Emergency Centres in the Western Cape Province, South Africa, between 2013 and 2014. South African Medical Journal, 108, 579.

http://www.samj.org.za/index.php/samj/article/view/12328 https://doi.org/10.7196/SAMJ.2018.v108i7.12969

[6] Sunyoto, T., Van Den Bergh, R., Valles, P., Gutierrez, R., Ayada, L., Zachariah, R., et al. (2014) Providing Emergency Care and Assessing a Patient Triage System in a Referral Hospital in Somaliland: A Cross-Sectional Study. BMC Health Services Research, 14, 531. https://doi.org/10.1186/s12913-014-0531-3 
[7] Makama, J.G., Iribhogbe, P. and Ameh, E.A. (2015) Overcrowding of Accident \& Emergency Units: Is It a Growing Concern in Nigeria? African Health Sciences, 15, 457-465. https://doi.org/10.4314/ahs.v15i2.20

[8] Coster, J.E., Turner, J.K., Bradbury, D. and Cantrell, A. (2017) Why Do People Choose Emergency and Urgent Care Services? A Rapid Review Utilizing a Systematic Literature Search and Narrative Synthesis. Academic Emergency Medicine, 24, 1137-1149. https://doi.org/10.1111/acem.13220

[9] Chandra, A., Mullan, P., Ho-foster, A., Langeveldt, A., Caruso, N., Motsumi, J., et al. (2014) Epidemiology of Patients Presenting to the Emergency Centre of Princess Marina Hospital in Gaborone, Botswana. African Journal of Emergency Medicine, 4, 109-114. https://doi.org/10.1016/j.afjem.2013.12.004

[10] Rosendale, K., Smith, Z.A., Davies, H. and Wood, D. (2011) The Effectiveness of the South African Triage Score (SATS) in a Rural Emergency Department. South African Medical Journal, 101, 537-540.

[11] Rominski, S., Bell, S.A., Oduro, G., Ampong, P., Oteng, R. and Donkor, P. (2014) The Implementation of the South African Triage Score (SATS) in an Urban Teaching Hospital, Ghana. African Journal of Emergency Medicine, 4, 71-75. https://doi.org/10.1016/j.afjem.2013.11.001

[12] Mullan, P.C., Torrey, S.B., Chandra, A., Caruso, N. and Kestler, A. (2014) Reduced Overtriage and Undertriage with a New Triage System in an Urban Accident and Emergency Department in Botswana: A Cohort Study. Emergency Medicine Journal, 31, 356-360. https://doi.org/10.1136/emermed-2012-201900

[13] Tshitenge, S.T., Ogunbanjo, G.A. and Mbuka, D.O. (2017) Corrigendum: The Effectiveness of the South African Triage Tool Use in Mahalapye District HospitalEmergency Department, Botswana. African Journal of Primary Health Care \& Family Medicine, 9, a1695. https://doi.org/10.4102/phcfm.v9i1.1695

[14] Twomey, M., Mullan, P.C., Torrey, S.B. and Kestler, A. (2011) The Princess Marina Hospital Accident and Emergency Triage Scale Provides Highly Reliable Triage Acuity Ratings. Emergency Medicine Journal, 29, 650-653. https://doi.org/10.1136/emermed-2011-200503

[15] Daniels, J., Zweigenthal, V. and Reagon, G. (2017) Assessing the Impact of a Waiting Time Survey on Reducing Waiting Times in Urban Primary Care Clinics in Cape Town, South Africa. Journal of Public Health in Africa, 8, 98-102. https://doi.org/10.4081/jphia.2017.639

[16] Horwitz, L.I., Green, J. and Bradley, E. (2010) US Emergency Department Performance on Wait Time and Length of Visit. Annals of Emergency Medicine, 55, 133 141. https://doi.org/10.1016/j.annemergmed.2009.07.023

http://ovidsp.ovid.com/ovidweb.cgi?T $=J S \& P A G E=$ reference $\& D=$ emed $9 \& N E W S=N$ $\underline{\text { \&AN }=2010042071}$

[17] Feldman, O., Allon, R., Leiba, R. and Shavit, I. (2017) Emergency Department Waiting Times in a Tertiary Children's Hospital in Israel: A Retrospective Cohort Study. Israel Journal of Health Policy Research, 6, 4-8. https://doi.org/10.1186/s13584-017-0184-X

[18] Bruijns, S.R., Wallis, L.A. and Burch, V.C. (2008) Effect of Introduction of Nurse Triage on Waiting Times in a South African Emergency Department. Emergency Medicine Journal, 25, 395-397. https://doi.org/10.1136/emj.2007.049411

[19] Hosseininejad, S.M., Aminiahidashti, H., Pashaei, S.M., Khatir, I.G., Montazer, S.H., Bozorgi, F., et al. (2017) Determinants of Prolonged Length of Stay in the Emergency Department; a Cross-Sectional Study. Emergency, 5, e53. 
[20] Mahsanlar, Y., Parlak, I., Yolcu, S., Akay, S., Demirtas, Y. and Eryigit, V. (2014) Factors Affecting the Length of Stay of Patients in Emergency Department Observation Units at Teaching and Research Hospitals in Turkey. Turkish Journal of Emergency Medicine, 14, 3-8. https://doi.org/10.5505/1304.7361.2014.58224

[21] Driesen, B.E.J.M., Van Riet, B.H.G., Verkerk, L., Bonjer, H.J., Merten, H. and Nanayakkara, P.W.B. (2018) Long Length of Stay at the Emergency Department Is Mostly Caused by Organisational Factors outside the Influence of the Emergency Department: A Root Cause Analysis. PLoS ONE, 13, e0202751. https://doi.org/10.1371/journal.pone.0202751

[22] IMO (2018) Achieving the 6-Hour Target for Patients Attending Emergency Departments in Ireland. http://www.imo.ie

[23] Van der Veen, D., Remeijer, C., Fogteloo, A.J., Heringhaus, C. and de Groot, B. (2018) Independent Determinants of Prolonged Emergency Department Length of Stay in a Tertiary Care Centre: A Prospective Cohort Study. Scandinavian Journal of Trauma, Resuscitation and Emergency Medicine, 26, Article No. 81. https://doi.org/10.1186/s13049-018-0547-5

[24] Sultan, M., Mengistu, G., Debebe, F., Azazh, A. and Trehan, I. (2018) The Burden on Emergency Centres to Provide Care for Critically Ill Patients in Addis Ababa, Ethiopia. African Journal of Emergency Medicine, 8, 150-154. https://doi.org/10.1016/j.afjem.2018.07.006

[25] Oliveira, M.M., Marti, C., Ramlawi, M., Sarasin, P., Grosgurin, O., Poletti, P., et al. (2018) Impact of a Patient-Flow Physician Coordinator on Waiting Times and Length of Stay in an Emergency Department: A Before-After Cohort Study. PLoS ONE, 13, e0209035. https://doi.org/10.1371/journal.pone.0209035

[26] Bukhari, H., Albazli, K., Almaslmani, S., Attiah, A., Bukhary, E., Najjar, F., et al. (2014) Analysis of Waiting Time in Emergency Department of Al-Noor Specialist Hospital, Makkah, Saudi Arabia. Open Journal of Emergency Medicine, 2, 67-73. https://doi.org/10.4236/ojem.2014.24012

[27] Guttman, A., Schull, M.J., Vermuelen, M.J. and Stukel, T.A. (2011) Association between Waiting Times and Short Term Mortality and Hospital Mortality after Departure from Emergency Department: Population Based Cohort Study from Ontario, Canada. BMJ, 342, d2983. https://doi.org/10.1136/bmj.d2983 